\title{
Systems for Construction \\ Lessons for the construction industry from experiences in spacecraft systems engineering
}

\author{
M. R. Emes ${ }^{*}, 1$, A. Smith ${ }^{1}$ and L. Marjanovic-Halburd ${ }^{2}$ \\ *Author to whom correspondence should be addressed \\ ${ }^{1}$ UCL Centre for Systems Engineering, Mullard Space Science Laboratory, \\ Holmbury St. Mary, Dorking, RH5 6NT, UK, Tel: 01483 204100, \\ m.emes@ucl.ac.uk
}

${ }^{2}$ Bartlett School of Graduate Studies, UCL Bartlett Faculty of the Built
Environment, Central House, 14 Upper Woburn Place, London, WC1H 0NN

Keywords: Systems Engineering, Project Management, Construction Management

This is an Accepted Manuscript of an article published by Taylor \& Francis in Intelligent Buildings International on 08/05/2012, available online: http://dx.doi.org/10.1080/17508975.2012.680428

\begin{abstract}
Construction projects are becoming ever more ambitious in terms of the size of structures, the number of requirements, the number and influence of stakeholders, and the extent to which technology is integrated into buildings. Whilst great buildings may historically have been designed and built by a single guiding mind - 'the architect' - modern buildings require teams of specialists to work together to develop ideal solutions. In these circumstances, to ensure that construction projects are delivered to time, to budget and to the requirements specified by the customer, the construction industry could benefit from adopting a systems engineering approach to design.

Based on 45 years of spacecraft instrumentation research and development and over ten years' experience teaching Systems Engineering in a range of industries, University College London's Mullard Space Science Laboratory has identified a set of guiding principles that have been found to be critical in delivering successful projects in the most demanding of environments. The five principles are: 'principles govern process', 'seek alternative systems perspectives', 'understand the enterprise context', 'integrate systems engineering and project management', and 'invest in the early stages of projects'. Behind these principles is a will to anticipate and respond to a changing environment with a focus on achieving long-term value for the enterprise. These principles are applied in both space projects and non-space projects (through UCL's Centre for Systems Engineering), and are embedded in UCL's teaching and professional training programme. These principles could contribute to the successful delivery of complex building projects.
\end{abstract}




\section{Introduction}

\section{History of Systems Engineering}

Whilst principles consistent with what is now referred to as 'systems engineering' (SE) have been applied as far back as for the building of the pyramids, the emergence of SE as a distinct discipline is usually associated with the management of technological projects during and after World War II. The first textbooks that referred to SE by name were published in the 1950s and 1960s (such as Goode and Machol (1957)). Traditionally, SE arose out of a recognised need to engineer functional systems that spanned different disciplines of engineering. With early projects primarily military and space based (Westerman 2001), SE was established as an approach to optimise complex systems with very clearly defined requirements, and with cost considerations of secondary importance. "The modern philosophy - the 'why' and the 'how' of today's systems engineering developed largely at NASA in the 1960s and 1970s" (Hitchins 2003). The early military/aerospace presentation of systems engineering emphasized the process involved rather than the holistic principles. The Defense Systems Management College in the US produced a Systems Engineering Management Guide (DSMC 1983) which explained the steps in SE, starting with 'requirements analysis' and ending in the 'synthesis' of alternative solutions. In fact, contemporary guides to systems engineering see the scope of SE interest continuing through deployment of systems into operation, maintenance and ultimately disposal (ISO/IEC 15288 2002).

Jenkins and Youle at Lancaster University had great expectations of the impact of SE, which have not yet been fully realized : "it is not unreasonable to claim that a new industrial revolution is now on its way with the advent of systems engineering, a revolution which is going to exert a major influence on how industry can be organized so as to integrate properly the potentialities of people and the possibilities of technology"(Jenkins and Youle 1971). SE has always drawn upon expertise from a broad range of disciplines, including in particular mathematics and the physical sciences. However, perhaps fuelled by the Lancaster school's optimism, SE seems to have become more ambitious in its scope in the last twenty years. From optimising well-defined, 'hard' systems with clearly specified requirements, aspects of SE are now being applied to offer insights into 'soft systems' with a significant human element and loosely defined requirements. The development of Soft Systems Methodology (SSM) was an attempt to address questions that, by definition, were outside the scope of SE as it was defined at the time (Checkland 1999).

\section{What is Systems Engineering?}

Founded in 1990, SE has a "not-for-profit membership organization founded to develop and disseminate the interdisciplinary principles and practices that enable the realization of successful systems" (INCOSE 2011) - The International Council on Systems Engineering (INCOSE). INCOSE defines SE as "an interdisciplinary approach and means to enable the realization of successful systems. It focuses on defining customer needs and required functionality early in the development cycle, documenting requirements, then proceeding with design synthesis and system validation while considering the complete problem: 
Operations, Performance, Test, Manufacturing, Cost \& Schedule, Training \& Support, Disposal. Systems Engineering integrates all the disciplines and specialty groups into a team effort forming a structured development process that proceeds from concept to production to operation. Systems Engineering considers both the business and the technical needs of all customers with the goal of providing a quality product that meets the user needs" (INCOSE 2011).

Central to the definition of systems engineering are the concepts of lifecycle, requirements, system and interdisciplinarity. In essence, a systems engineering approach to a project recognises: the different phases in a project from conception to disposal (lifecycle); the need to strictly identify and track satifisfaction of stakeholder needs (requirements); the way in which a delivered system can be partitioned into a hierarchy of subsystems and elements, with the functions required from a system mapped to subsystems, interfaces defined, and responsibility for delivery of each subsystem allocated to a specific individual or enterprise (system); and that each subsystem will need a different blend of specialist skills to deliver it (interdisciplinarity).

\section{Systems Engineering in Construction}

Traditionally, building design solutions have been driven by prescriptive terms governing the construction process (with cost and time to deliver being particular concerns); rather little emphasis has been placed on the expected performance of the end product (Augenbroe 2011). Building regulations across the world are becoming increasingly performance based, however. The upfront formulation of performance requirements and the subsequent management of a process that guarantees their fulfilment through dialogue between designers, engineering managers and building managers is impossible without a proper framework accommodating the definition of performance requirements and the methods by which these will be measured. Augenbroe (2011) identifies a disconnect between demand (client) and supply (designers) throughout the building delivery process, due to a lack of a formal basis for both expressing expectations and establishing that expectations had been fulfilled.

Building projects are becoming ever more ambitious in terms of physical size, complexity of structures, and materials used. Large buildings are increasingly 'intelligent', integrating many technologies such as for security, safety, communications, comfort and entertainment. Furthermore, the number of requirements and the number and influence of stakeholders continues to grow. For example, social media allow the general public to express opinions on building projects in an instant and to share them on a global scale. At the same time, environmental legislation is becoming increasingly strict whilst expectations on time and cost to deliver projects leave little room to manoeuvre.

Poor performance in construction projects is common (Meng 2011) and most research in this area only focuses on time and cost performance. Recent cost and time data for the UK are shown in Figure 1 and Figure 2 (Folwell, Sharp et al. 2011). It is clear that only around $50 \%$ of projects are completed to budget, and $50 \%$ of projects are completed on time. Project quality is also a critical measure of project success (Tao and Tam 2011) and decreasing quality of construction is 
a worldwide phenomenon, often caused by inappropriate mechanisms of project delivery, bad design, poor project supervision, inadequate material and poor workmanship (FIDIC 2004). In construction as in other industries, engineering design is critical to performance. However, unlike manufacturing, engineering design is often carried out separately from production (or build) and consulting engineering firms usually have little control over most of the projects in which they engage (Torbett, Salter et al. 2001).

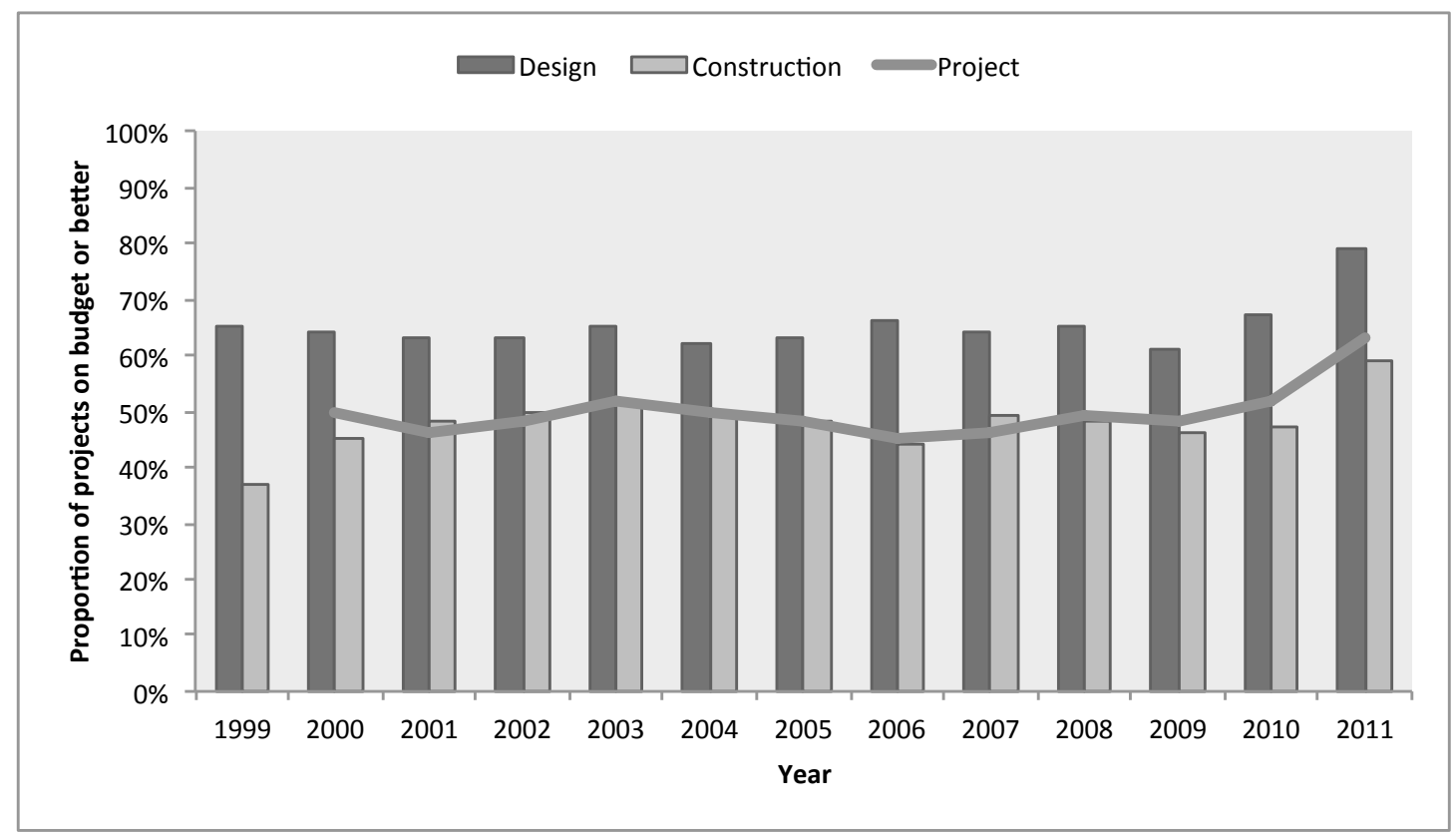

Figure 1: Cost predictability for UK construction projects

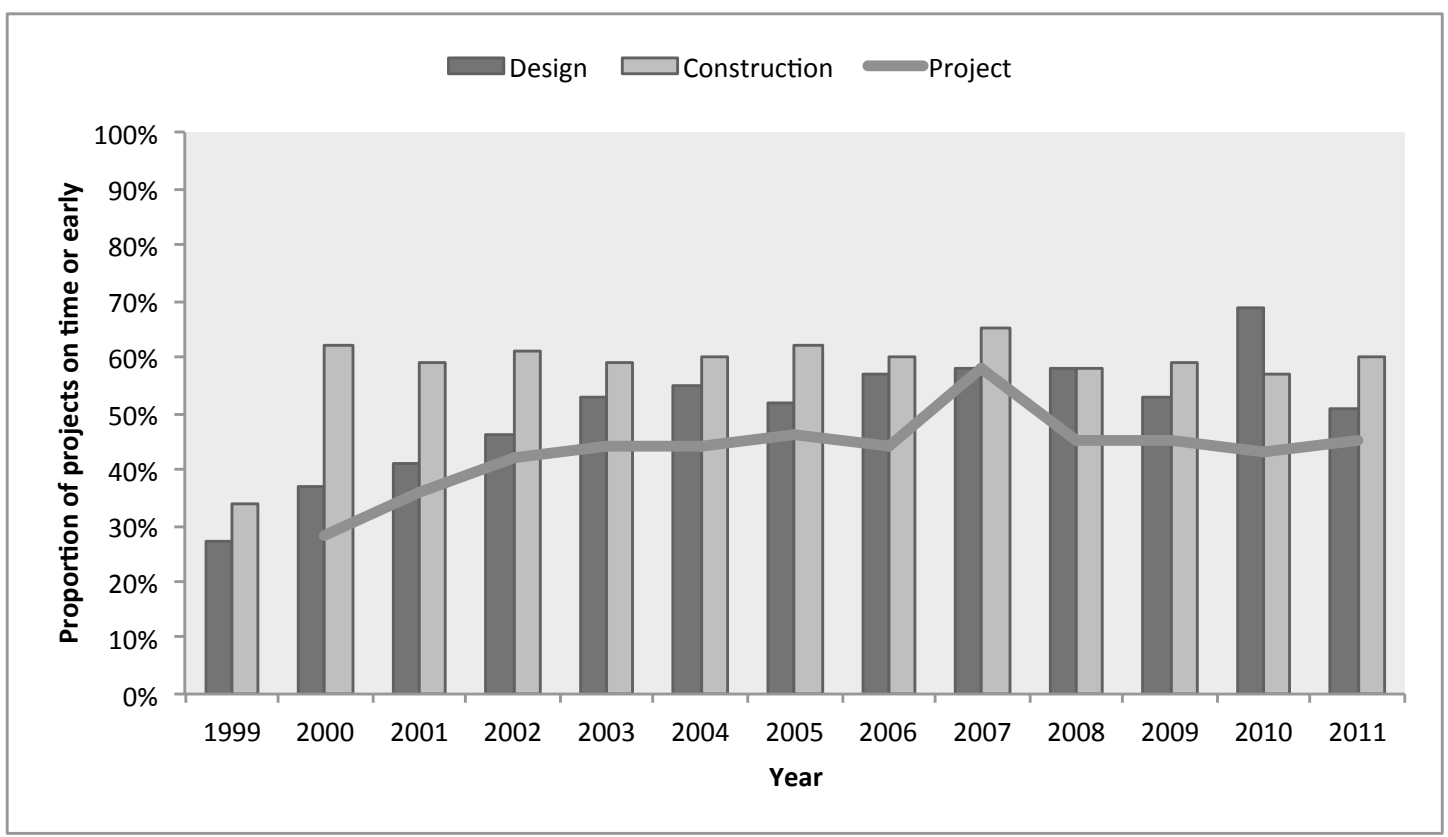

Figure 2: Time predictability for UK construction projects

For comparison, in the defence sector, where in the last ten years systems engineering has been increasingly adopted as a critical philosophy in the planning and delivery of complex projects, cost performance in UK projects has significantly improved. For 33 projects approved in or before 2001, cost to 
complete projects was projected to be $16.8 \%$ greater than budget, whilst for 30 projects approved since 2002, cost to complete is projected to be just $2.8 \%$ greater than budget. Schedule performance remains poor, however, with 8 out of the 13 largest projects for which data was available forecasting delays to inservice date relative to the expected in-service date at the time of approval (National Audit Office 2011). However, the long duration of most defence projects and the degree of political influence exerted on them mean that it will take a long time to understand the real impacts of system engineering initiatives in defence acquisition and defence project delivery.

Although recognition of the value of SE for construction is beginning to grow, the construction industry has been slow to adopt the principles and processes of SE advocated by practitioners and academics from the sectors traditionally associated with SE - in particular aerospace and defence.

Yahiaoui et al (2006) argue that adoption of the traditional SE V-diagram (Figure 3 ) during building design and construction process would help optimize the trade-offs during building lifecycle since SE V-diagram allows for transformation of operational needs into a system performance parameters specification and integration of different functionalities requirements and related design parameters.

The benefits of SE application at the component level of building design has been discussed by de Wilde, Augenbroe, and van der Voorden (2002). These authors suggest that four main SE activities should be conducted at the component level:

1. analysis of objectives and constraints that control the selection of components, and specification of appropriate performance indicators;

2. development of an 'option space' that consists of combinations of building design(s) and energy saving building components and a parameterization of these combinations;

3. determination of the performance of these combinations;

4. selection of the most desirable combination of building design and components.

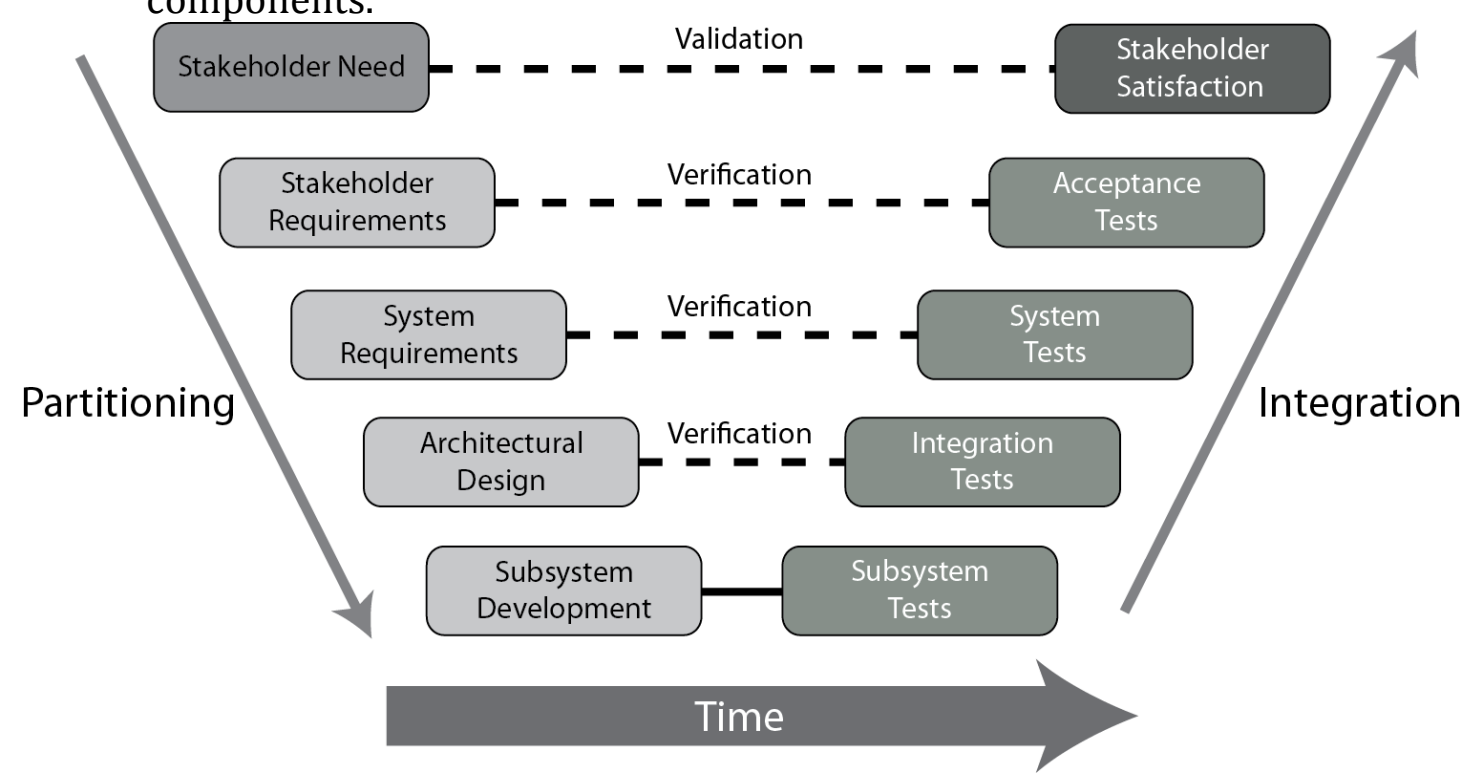


In an attempt to incorporate high-level functional requirements in the building design process, Augenbroe (2011) proposes an aspect system approach, where each functional requirement of a building can in theory be linked to one or more 'aspect systems' (performance-criterion focused aggregations of technical systems) thus allowing the quantification of all relevant performance indicators (Figure 3). This is analogous to the traditional process of functional analysis and functional decomposition practised in the aerospace and defence sectors for many years (NASA 2007).

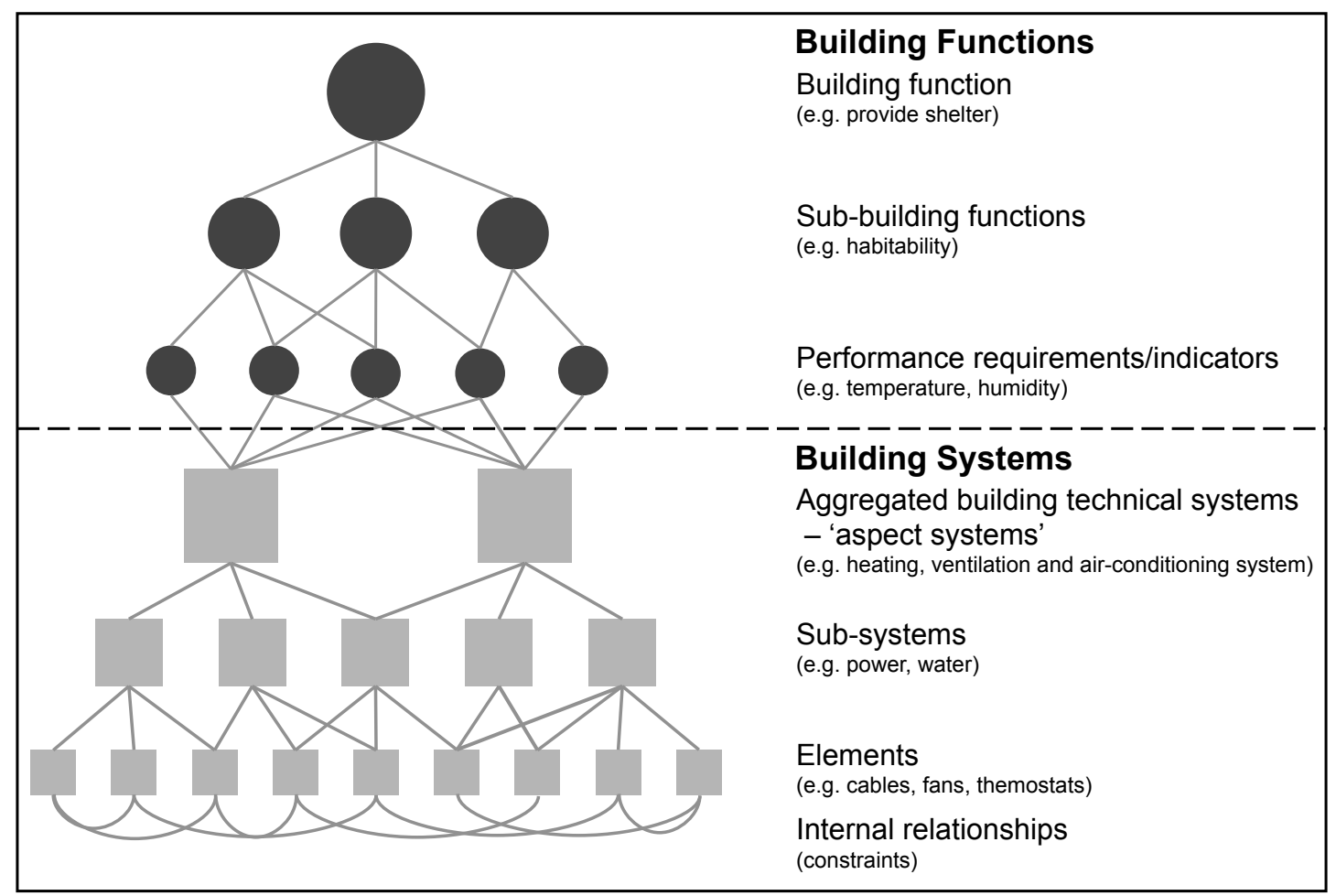

Figure 4: Overview of the Aspect System approach, adapted from Augenbroe et al (Augenbroe, Malkawi et al. 2004; Augenbroe 2011)

This growing trend for aspects of aerospace and defence systems engineering to be adopted in construction indicated to the authors that a broad approach to systems engineering focused around a number of principles derived from experience in the space sector might usefully be applied in the construction industry.

\section{Systems engineering in space}

The space domain has a rich heritage in developing best practice for systems engineering. During the space race between the Soviet Union and the United States in the 1950s and 1960s, a significant amount was invested in getting to grips with the technological challenges involved in delivering new capabilities in the harshest environmental conditions, particularly by the United States (which largely explains why they won the race to the moon). In the decades that followed, many space agencies, in particular the US National Aeronautics and Space Administration (NASA), the European Space Agency (ESA), the Russian Federal Space Agency (ROSCOSMOS), the Japanese Space Agency (JAXA) and the Chinese National Space Administration (CNSA) developed significant capabilities 
(including manned spaceflight for the US, Russia and now China), whilst countries around the world rely on spacecraft for communications and remote sensing (for example for climate monitoring and global positioning systems). All space technologies rely on the development of complex systems with extremely high reliability, with projects almost always heavily constrained by budget and launch schedules. Successful delivery of many space exploration and science missions has been assisted by an extensive body of knowledge including the NASA Systems Engineering Handbook (Shishko 1995; NASA 2007) and European Space Agency standards such as the ECSS (European Cooperation for Space Standardization 2011).

\section{The Mullard Space Science Laboratory}

The focus of this research was UCL's Department of Space and Climate Physics (Mullard Space Science Laboratory - MSSL). MSSL is a world-leading research organisation and is the UK's largest university-based space research group. It delivers a broad, cutting-edge science programme, underpinned by a strong capability in space science instrumentation, space-domain engineering, project management and systems engineering. Since its formation in 1966, MSSL has been involved in more than 35 scientific space missions and over 200 rocket launches. MSSL develops and tests hardware and software, usually as part of an international consortium, with engineers working alongside scientists to ensure that the instruments produced address key questions in modern space science. Post-launch support that is linked to pre-flight and flight calibrations enables scientists to understand the responses of the instrument, greatly benefitting the analysis and interpretation of the data.

Project performance at MSSL has been very good. In terms of quality, $100 \%$ of MSSL instruments have had successful development and environmental test programmes and have been accepted by the relevant space agencies; $100 \%$ of MSSL instruments have worked successfully at switch-on when the spacecraft itself has achieved orbit (and been operational). In terms of resources used, the nature of the research performed and the typical relationship with research councils means that, under certain circumstances, extra funds can be made available over and above the original budget. Furthermore, MSSL occasionally chooses to support instrument developments from internal resources for strategic reasons. Cost-based performance indicators are therefore difficult to use. Nevertheless, MSSL has performed extremely well in a limited-resource environment. In terms of schedule performance, while delivery schedules are often negotiated (which is standard practice for the domain) and space agencies typically include margin in this area, MSSL has not been responsible for any major launch delay.

\section{Comparison between space and construction domains}

Whilst construction projects and technology development projects for spacecraft instrumentation may seem worlds apart, there are in fact some common characteristics.

One-off, customised developments

Space science missions are conceived with the idea of getting access to data never previously available. This may be provided, for example, by launching 
spacecraft with new and improved imaging technologies (higher resolution sensors, better cooling systems, etc.). Even if elements of the system can be reused from previous missions, the project to develop the instrumentation by integrating a package of technologies into a high-performance, high-reliability system under tight volume, mass and cost constraints is likely to be unique. For the next project, the demands of the customers (the research community) and the constraints of the system will be different. Similarly, in construction, although the technologies used may be well known, the architectural vision or context for each project will be unique (even if there are elements of design reuse within projects such as housing estates). This means that for both space science projects and construction projects, each project will have its own challenges, which are often difficult to anticipate and without careful management can lead to significant cost and time increases. Management of the teams is a particular challenge for construction projects, since teams are often formed in an ad hoc manner, changing from project to project.

\section{Validation challenges}

For construction projects, the project lifecycle tends to be sequential, with limited concurrency (overlap) between lifecycle stages (see Figure 3). The ability to build prototypes, test them, learn from them and thereby improve the design is relatively limited (although computer software can be very useful for simulating built environments). In design of small consumer technology products such as mobile phones and software products, on the other hand, much more iterative lifecycles are possible, with prototypes and focus groups or lead user groups contributing to the design process, to ensure that the quality of the end product meets the expectations of the user. This means that for construction projects, it is hard to get feedback regarding the quality of the end product relative to customer expectations (shown as 'validation' in Figure 3) until it is too late to economically address any major shortcomings. Customers may approve the conceptual system (the design), but the as-built system (the deployed system) is bound to diverge from the designed system in certain aspects (Martin 2004). Owing to the inaccessibility of the space environment, the same difficulty in validating the final system is true with space science projects. At least with these, however, there is generally the ability to develop subsystems concurrently and to test these in simulated environments (such as vacuum chambers, vibration test facilities, etc.) With construction projects, the ability to test the performance of any of the subsystems of a building before the building has been built is limited. This is a major problem if installation and testing of one of the subsystems (such as the power subsystem) identifies a deficiency in the architectural design. Whereas the general impossibility (repairs by astronauts to the Hubble Space Telescope being a notable exception) of fixing failed systems in orbit motivates spacecraft engineers to deliver extremely high quality products to the launchpad, the possibility of improving aspects of building performance after delivery can lead to complacency in design. The London Millennium Footbridge, for example, initially cost $£ 18 \mathrm{~m}$, but required a further $£ 5 \mathrm{~m}$ of modifications when it was found to sway unacceptably under synchronous lateral excitation -resonance seen when large numbers of pedestrians walk in step (BBC 2012). 


\section{High-value projects}

Both major construction projects and space science projects require a large amount of investment from one or a few major customers; pressure is high to deliver a quality system on time and to budget. There is a need to be flexible to accommodate the needs of major stakeholders. For space science missions, this may be manifested in requests from the science community to extend quality or features of instrumentation. For construction projects, this may take the form of changes to user requirements mid-way through the project. In both cases, suppliers are torn between the desire to deliver a quality product that satisfies the customer's needs and the wish to deliver on time and to budget. Project performance against the three dimensions (quality, cost and time) will influence supplier reputation and potential for future work. Perhaps the greatest challenge is the fact that changes to requirements during the project may have knock-on effects that are not easy to anticipate and evaluate.

\section{MSSL Principles of Systems Engineering}

UCL Centre for Systems Engineering (UCLse) is a university-wide centre of excellence for systems engineering and is hosted within MSSL, regularly reviewing experiences from MSSL space projects. A recent UCLse project has drawn together these experiences and identified five underlying principles that reflect best practice in project management and systems engineering at MSSL. Although they are derived from the space domain, it is felt that these principles are widely applicable and are fundamental to the management of systems engineering endeavours. They now provide a coherent vision of the UCLse approach to Systems Engineering and its management. UCLse has also incorporated these principles to good effect into its continuing professional development programme and masters programmes with delegates and students from a wide range of sectors including defence, rail, aerospace, telecommunications, consumer electronics and energy. The principles are described in turn below.

\section{Principle 1: Principles govern process}

\section{Statement of principle}

Systems engineering and its management is facilitated through the development of processes. However, over-dependence on processes in situations where they do not apply (or are clearly not designed for) can cause problems. Processes should be seen as enabling rather than deterministic: individuals need to be both accountable for their actions and given a level of discretion in the application of high level processes. When adapting a generic process to a particular situation the individual must first understand the principles that underpin the process. Principles should be derived from experience and analysis of past endeavours including development failures. It is essential to capture these lessons and continuously improve current processes. 


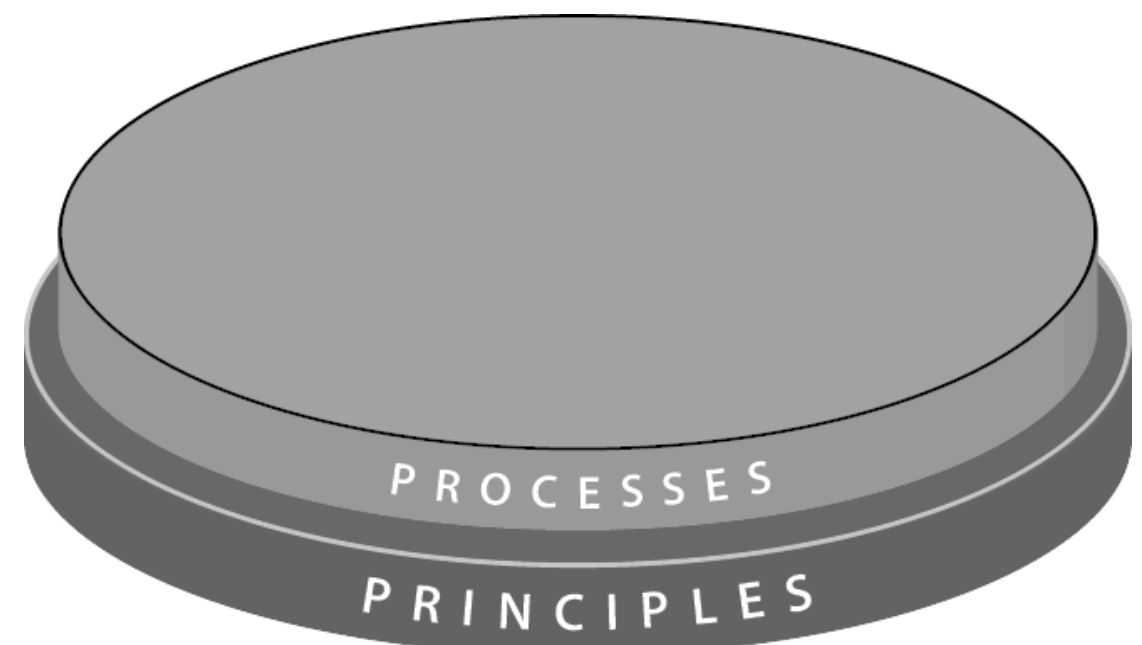

Figure 5: Principles govern process

\section{Justification of principle}

When the business environment changes, the old rules become less applicable. When this happens, we rely on underlying principles to guide us. Systems engineers and even specialist engineers should not become unquestioning cogs in a machine. Processes can become a liability if not kept up to date. Engineers are capable of great creativity, and they should be empowered to apply this creativity to processes as well as the products they design. The project team and the organization in which it resides must be a learning organization (Senge 1990), striving for continuous improvement of its processes in the search for quality (Liker 2004).

Processes and standards are valuable, however, to facilitate exchange of information with customers and project partners. Especially in demanding environments such as space, very high levels of reliability and quality are essential and standards and common processes help to achieve this. MSSL learns from publications like the NASA Systems Engineering Handbook (NASA 2007) and the INCOSE Systems Engineering Handbook (INCOSE 2011) and embraces standards like ISO 9001(International Organization for Standardization (ISO) 2008), and the European Space Agency's ECSS standards (European Cooperation for Space Standardization 2011). Standards embody the codified knowledge of past generations of expert engineers. If all engineers were to challenge standards and processes routinely, too much time would be spent reviewing techniques rather than applying proven techniques; this would be inefficient at best and dangerous at worst. Sometimes, such as in safety-critical systems, strict adherence to a process is mandatory. Here, where an individual finds the process to be inappropriate he or she should seek resolution (but not act independently). What is the right amount of process review to allow? This is analogous to the question 'what is the right amount of tailoring to a process' (INCOSE 2011). The key is to empower 'process innovators' that understand what processes are trying to achieve and can bring knowledge or experience to the problem to identify areas for valuable improvement. Sometimes, the best people to suggest improvements will be those experienced in applying the existing process for years - those familiar with the strengths and weaknesses of the current ways of working. Other times, new employees or outsiders (such as consultants) may 
identify weaknesses with existing practices to which experienced staff have become desensitized.

The process of continuous improvement is applied at MSSL through a review process at the end of every project to reflect on the successes, challenges and areas for improvement in each project. Lessons learnt from these reviews feed back into regular programme review meetings attended by all project managers, giving the opportunity for a collective body of knowledge and best practice to develop.

In space projects, environmental qualification of a design is usually an essential part of the development process and involves subjecting a test item to higher levels of stress (such as vibration) than they would expect to experience during launch. Ideally, this would mean building a special item purely for testing and then discarding it, since the testing process may have weakened it. In this way, the design rather than the test item is qualified. To save resource, an increasingly common approach is to move to a 'protoflight' model philosophy where the flight hardware is tested to a lower level, albeit still somewhat above flight levels. In this way the risk of degradation due to test is reduced and it is now the item rather than the design that is qualified. On a number of occasions items have failed either the qualification or protoflight qualification tests. The formal process demands repair and retest but careful consideration is needed at this point. Repetition of testing could degrade the strength below a flight-acceptable level. Furthermore, such repair would take time and resource, and the consequences of a further failure (due to the weakening) need to be considered. At this point, one should fall back on the principle underlying the testing process - namely that the activity is meant to reduce risk not increase it. Through analysis of the failure and argument that the situation is sufficiently well understood that an alternative course of action is preferable, some very difficult situations have been managed. For example, during a protoflight vibration test, several components on a printed circuit board became detached. On analysis it was discovered that all had a common and simple mounting problem. Rather than risk weakening other components with a full-retest, the board was repaired and tested at a much lower level with the full agreement of the space agency involved (a second failure would have set the project back two months while a new item was built and tested).

MSSL also looks outside its own projects for sources of inspiration, in the principle of Open Innovation (Chesborough 2003). UCLse and the Technology Management Group at MSSL continuously reviews best practice in Systems Engineering and Project Management and feed this into internal (and external) training courses and programme review meetings.

\section{Example of relevance of principle for construction}

In the push towards zero-carbon buildings, zero-carbon technologies are arriving in boxes from Germany. Although the process has been designed to facilitate carbon reduction, there may be a lack of local expertise to effectively integrate the technologies into the building system. Although the process may have been designed on the basis of some sound principles and may be well 
understood in Germany, its local effectiveness may be limited by poor understanding of these principles at the point of integration.

\section{Principle 2: Seek alternative systems perspectives}

\section{Statement of principle}

To enhance understanding, it is worthwhile exploring a range of systems perspectives, viewpoints or abstractions, including the additional capability and uncertainty that is uncovered by incorporating humans in systems. Complexity can be managed through a 'divide and conquer' approach, breaking systems into interacting systems elements and understanding the function of those elements, their interactions (both planned and unplanned) and how the elements collaborate to deliver the system's emergent properties. There will be many options for how a system is partitioned - each with different strengths and weaknesses. It is important to recognise the importance of overlapping hierarchies (elements that are parts of more than one system and require appropriate management and control). The time dimension can be a valuable source of insight. The nature of the solutions to similar problems faced in the past should be noted, and technology trends recognised that will influence the next generation of solutions. In a changing world, system developments must accept the need for evolving requirements and include flexibility in delivered systems to adapt to changing needs during the system life.

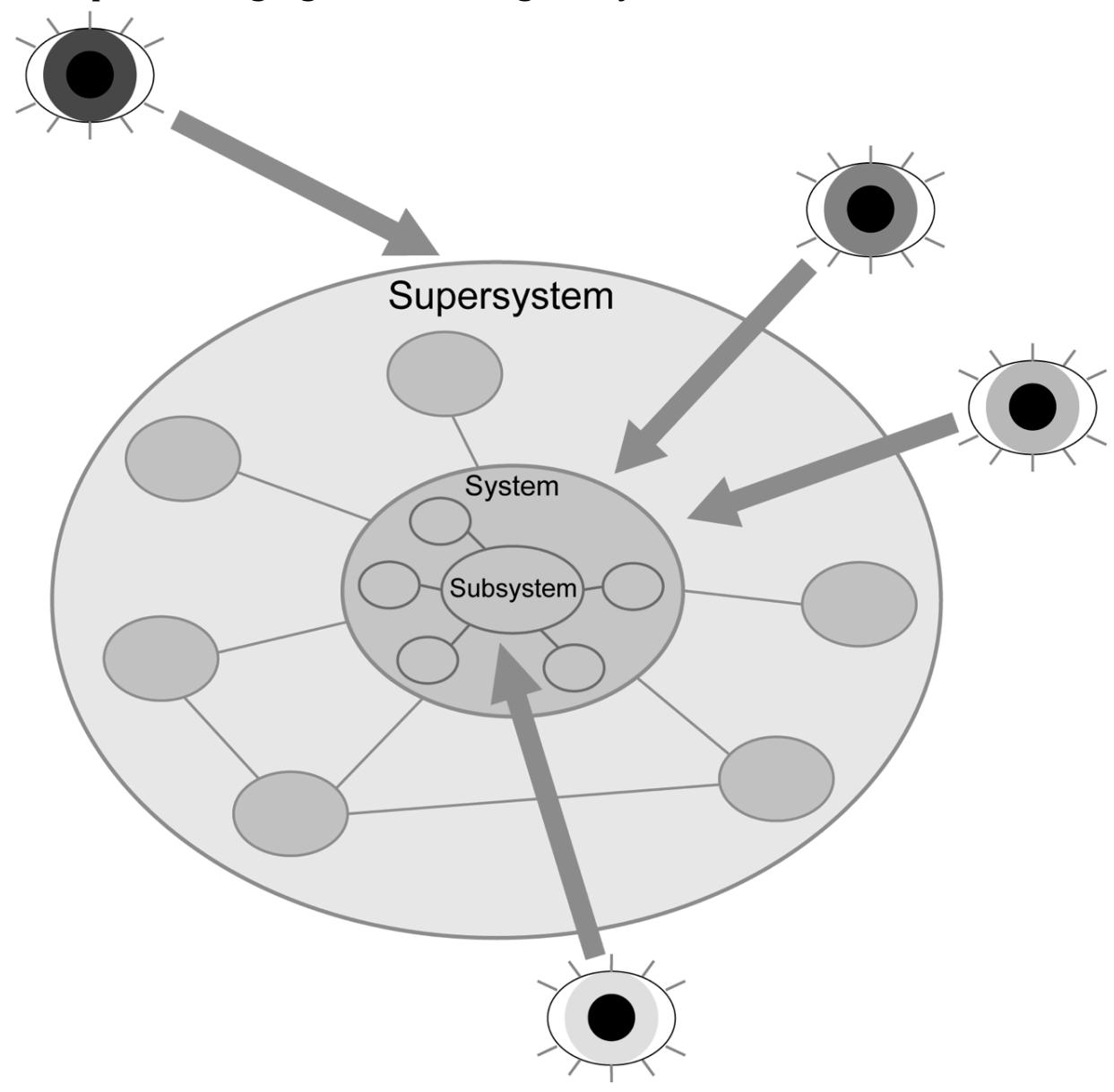

Figure 6: Seek alternative systems perspectives 


\section{Justification of principle}

Systems are, by definition, more than the sum of their parts (Hitchins 2003). One must be sensitive to cause and effect and the repercussions (sometimes distant in time and space) of making changes to one part of a complex system (Sterman 2000). Nevertheless, the pragmatic process of developing systems under time constraints requires systems to be partitioned into manageable pieces which can be designed and manufactured by separate groups before being reassembled into a working whole.

Systems can be defined in many different ways, depending on how the system is partitioned internally and where the system boundary is drawn (Martin 2008), and this flexibility should be explored to maximize understanding of a system. Sometimes there is pressure to adopt a single viewpoint when developing a system, to make sure that from that viewpoint the system's performance is excellent. When designing a car or an aircraft, for example, the needs of the driver or pilot may seem to outweigh all others from a comfort and safety perspective. Or, a market may be so saturated with similar product offerings that the target customer may be quite specific (such as for technical books or some financial products). In other cases, a trend-setting manufacturer may decide to promote a new product in a particular way, promoting some aspect of form or function above all else. In all of these situations, however, the apparent focus on one stakeholder is an illusion. In reality, all products designs represent a compromise between offering performance in one dimension and offering performance in another For many products, from consumer electronics to buildings, this compromise may be most obvious in the distinction between form and function - is it aesthetically appealing, and how well does it meet its functional requirements? In general, the requirements of different stakeholders will conflict, will be uncertain and will change over time, not only because their needs change in an unchanging environment, but also because the environment changes owing to technological, economic or political changes. The challenge in multi-criteria decision making like this is to understand how to trade off performance in one dimension against performance in other dimensions in an uncertain environment, with a focus on delivering a valuable system design (Curran, Abu-Kias et al. 2010).

During a three-year research project investigating technology management in instrumentation supply chains (an Intersect Faraday Partnership project sponsored by the UK Engineering and Physical Sciences Research Council and the UK Department for Business Innovation and Skills), MSSL developed a method for planning new multi-stakeholder technology developments. Each solution concept was scored according to its effectiveness from the perspective of each stakeholder against each of their requirements, and weighed against implementation factors of cost, risk and time to deliver (Emes 2007). This approach incorporated Technology Roadmapping (Phaal, Farrukh et al. 2003) and Scenario Planning (van der Heijden 1996) to help plan for a technology development in an uncertain future. This is valuable whether we are massmarket suppliers of oil like Shell (2011), consumer electronics manufacturers like Samsung (Moeller and Brady 2007), or deliver one-off projects such as in the aerospace, defence, construction or IT domains (NASA 1997). 
A key challenge is achieving the right balance between fixing requirements to maintain design integrity in a complex system, and allowing flexibility to enable the system to adapt to a changing environment and changing customer requirements. We should try to view a system development project in terms of possible successor projects, and seek wherever possible to employ design concepts that will be reusable (to the extent that this makes sense commercially - the cost of design for reuse should be weighed against the anticipated benefits).

The above principle has informed and shaped MSSL's approach to the development of plasma analysers. While such analysers, common in the area of space plasma physics, can be configured in many ways, they generally lead to instruments that weigh around 1-5 kg. By considering trends in space mission drivers, opportunities for re-use in emerging space programmes and new technologies, a programme of miniaturization of analysers was embarked upon with analysers weighing $\sim 0.1 \mathrm{~kg}$ and able to be flown on nanosatellites (with total mass less than $10 \mathrm{~kg}$ ). This programme is now well past its proof-of-concept stage with launches planned on several missions, including a 50-nanosatellite project.

Seeking alternative systems perspectives can be a very creative process, such as embodied by product development firm IDEO's approach to design (Kelley 2001) and can be facilitated by primary research in which important stakeholders are identified and interviewed (both before and after prototype systems are developed - iterative approaches to development are encouraged wherever possible to facilitate this feedback). Both qualitative approaches (such as depth interviews and focus groups) and quantitative approaches (questionnaires to a carefully designed sample of a population of interest) can be useful here.

According to research by the Standish Group into IT projects, 'user involvement' is the single most important factor in determining whether a project completes successfully (The Standish Group 1994). Often, customers do not fully understand what their needs are (Workman 1993), both for major one-off projects and for mass-market production (there are many examples of successful products that were created in spite of, rather than because of, market research findings such as the Sony Walkman). This is particularly true for the customers of system integrators. In this case, an important output of the system development is establishing a set of value-adding system requirements, and flowing these requirements down in a way sensitive to the needs and capabilities of the supply chain (Emes, Hughes et al. 2005; Emes and Smith 2005). Soft systems methodology can be used to good effect to explore multiple worldviews of a system (Checkland 1999; Checkland and Scholes 1999; Wilson 2001) and to develop rich pictures that identify areas of potential conflict.

Seeking alternative systems perspectives can also be a more mechanistic process, in which aspects of a system are considered in a hierarchical sense, such as using hierarchical holographic modelling (Haimes 2009). In each case, assumptions must be identified and challenged to ensure we have the best possible understanding of the system before embarking on a system 
development. Enterprise architecture frameworks such as Zachman, for information technology and general enterprise architecture (Zachman 2012), the US Department of Defence Architecture Framework (DoDAF 2012) and TRAK (Rail) Enterprise Architecture Framework (TRAK 2012) have been developed to encourage a broad range of perspectives to be considered in a consistent manner between projects in a range of industry sectors. TRAK, for example, has a set of five 'perspectives' (enterprise, concept, procurement, solution and management) each with a number of 'viewpoints' (22 in total). Although the business case is weak for MSSL to adopt a formal architecture framework developed for a different domain, MSSL is exploring the idea of using a basic set of standard viewpoints that encourage different perspectives to be considered; consistent with the idea that 'principles govern process', however, flexibility to explore additional perspectives will be maintained. In parallel, MSSL is taking an interest in the emerging European Space Agency Architecture Framework (Gianni, Lindman et al. 2011).

\section{Example of relevance of principle for construction}

Architects liaise with the customer, and may develop many different views of a system at the concept stage. Perhaps more could be done to probe the requirements of different stakeholders, however, both in terms of understanding their performance needs when a building enters service, and in terms of anticipating changes to stakeholders' needs over the life of the building. Buildings should be designed with potential for reconfiguration or reuse in mind. This includes not just the physical layout (location of walls, windows, etc.) but also the provision of infrastructure for water, gas, electricity and information technology. Design should be sensitive to potential changes to infrastructure standards (such as fibre-optic cables replacing copper wire for broadband connections).

\section{Principle 3: Understand the enterprise context}

\section{Statement of principle}

System developments are undertaken by an organisation (usually a business) because they give benefits to that organisation. It is essential to understand the organisation's objectives and constraints when determining the optimal solution. The system development system (the combination of enterprise, collaborators and supply chain that develops the system solution) must be configured to be fit for purpose within whatever constraints exist. Soft systems approaches may be applied to facilitate the accommodation of a systems development project within an organisation. 


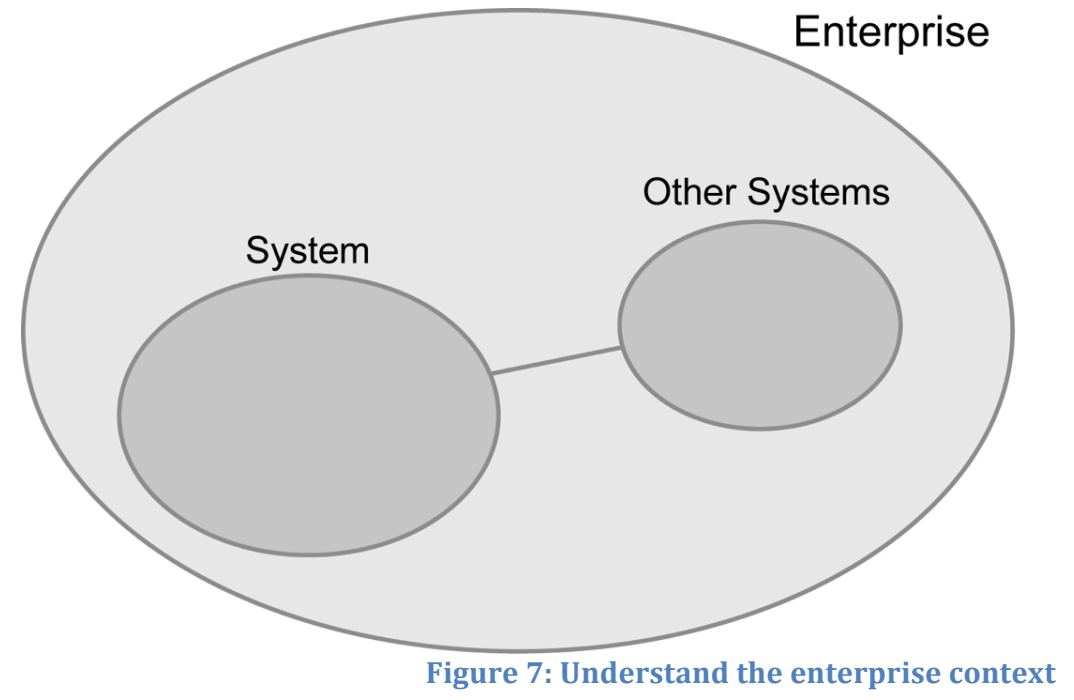

\section{Justification of principle}

Projects create systems, and these projects are subsystems of an enterprise, and therefore need to be sensitive to the needs of the enterprise. Businesses exist to create value for their owners (for large companies, the owners are usually shareholders) (Brealey, Myers et al. 2005). Even most not-for-profit organisations have a primary focus on survival (income exceeds spending) and growth (this is not true for organisations set up for specific short-term projects).

A project-based enterprise should be designed to maximise its effectiveness in delivering valuable projects (Giachetti 2010). It is perhaps easy to forget when worrying about design choices in a technical system that every decision will have an impact on the performance of the parent enterprise. Early or late delivery of projects, delighting or disappointing the customer, inspiring or burning out the project team, and identifying or missing clever ways to reuse technology can all have major implications on an organisation's ability to receive income or to spend money (now or in the future).

MSSL is part of a major UK University whose goals include education, research and wider social and economic impact. It is vital for the laboratory that it aligns to these goals so we have embraced their breadth through a number of initiatives including:

- Technology research spun-out to support the UK space industry through subcontracted, specialist engineering

- A Masters-level programme of education that is aligned to our research interests

- An outreach programme that encourages future interest in space through the dissemination of our research and technology interests

- A CPD programme in Systems Engineering, Systems Engineering Management and Project Management.

Organisations should also look outside their own enterprises to understand the external environment. What is the competitive landscape, for example? When bidding for a project, what will be the likely competing bids, and how can a proposal maximise its perceived value relative to other bids? For a new product 
development, how might competitors react? For competitor new product developments, what would be the best response? Systems engineers in a commercial organisation should be alert to the possibility of exploiting technology developed elsewhere, or selling or licensing technology to competing organisations, with at least a basic understanding of the concepts of valuecreation, cost-benefit analysis, and intellectual property.

\section{Example of relevance of principle for construction}

Construction projects should look beyond the performance of individual projects (in terms of quality, cost and time to deliver) to understand the wider impacts on their supersystems - i.e. the companies involved. This might mean taking measures towards corporate social responsibility like carbon reduction or investing in schemes like 'considerate constructors' (CCS 2012). These should be seen as investments; they may make the project take longer or cost more to complete, but improved perception of the project amongst public, government and other stakeholders may lead to further profitable business in the future.

\section{Principle 4: Integrate systems engineering and project management}

\section{Statement of principle}

Project management and systems engineering management are highly overlapping endeavours. In both cases their general scope is the fitness for purpose of the end product and the efficiency of its production. Different organisations define differently the responsibilities of project managers, programme managers, systems engineering managers and chief scientists. Nevertheless, there needs to be cooperation and coherence in the management structure, which recognises the differing approaches of (systems) engineering and (project) management. While project management is typically based around a deterministic breakdown of the required activities and the creation and delivery of a causal network of such activities against defined timescales, engineering often involves iterative development with concurrent progress across a broad front. This difference can lead to real difficulties when reporting progress. Projects are systems, and need to be managed with a similar blend of science, heuristics (rules of thumb based on lessons learnt and best practice) and creativity. Too often projects are seen deterministically, when in fact there are major sources of uncertainty (threats and opportunities) that could have significant implications for optimisation. The optimum system depends on the project design, and the optimum project design depends on the nature of the system to be delivered. This interdependency between optimum system and optimum project needs to be recognised and managed. 


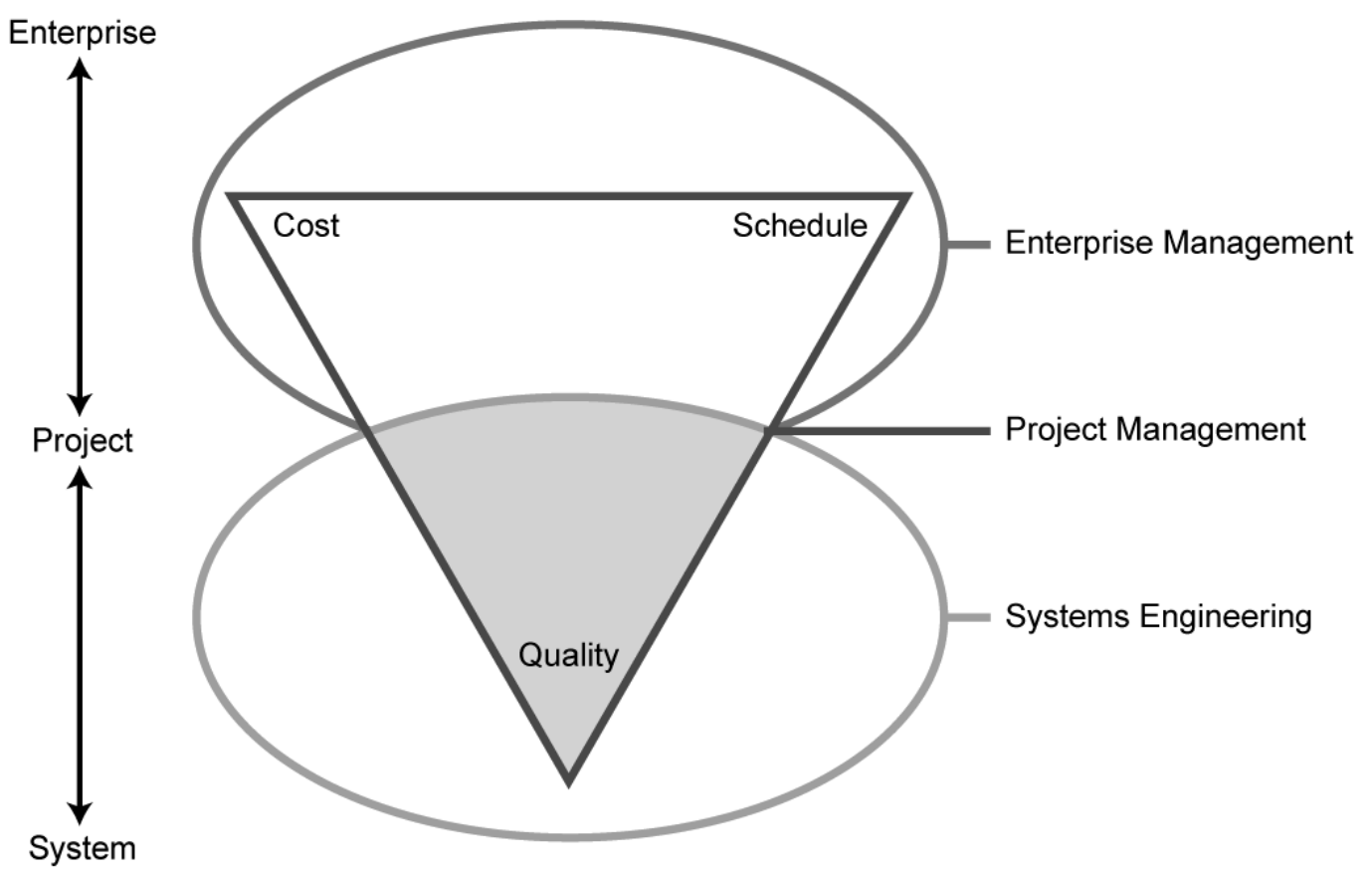

Figure 8: Integrate Systems Engineering and Project Management

\section{Justification of principle}

The famous project triangle that shows the interplay between Quality, Cost and Schedule considerations gives a useful backdrop for a discussion of the relationship between Systems Engineering and Project Management. As shown in Figure 8, the Systems Engineering role has a primary responsibility for ensuring that the delivered system or product has the required quality or performance level, with the Project Management role having primary responsibility for ensuring that the project is completed according to the agreed budget and schedule. There is a danger here that both systems engineers and (even more so) project managers have an insular view of the project, and lose sight of the project's role in delivering value to the wider organisation. The impact of this can be a willingness to overwork staff and to de-prioritize strategic activities in favour of a greater focus on project work, which may allow the project to be delivered on schedule, but more often than not will not allow the project to be delivered on budget if all costs are correctly allocated (such as using activity-based costing to capture the real project costs including the appropriate share of labour, materials, equipment and overheads (Kee 1999)). There may also be a tendency amongst some project managers to favour visible progress (i.e. manufacturing) at the expense of planning. There should be a symbiotic relationship between the Systems Engineering and Project Management roles, with the systems engineer helping the project manager to understand the implications of budget and schedule decisions on delivered performance, and the project manager helping the systems engineer to understand the implications of technical decisions on overall budget and schedule.

Within MSSL, Systems Engineers and Project Managers work closely in very integrated teams. Both are generally recruited from a common pool of either applied space scientists/ instrument scientists or space engineers. While 
responsibilities are well defined, cooperation and support is part of the laboratory's culture. A long and common exposure to space mission lifecycles has meant that a level of 'unconscious competence' has been achieved reinforced through dialogue, debate and experience.

The relationship between a systems engineer and a project manager is just one example of roles with overlapping interests. At a higher level there is a similar tension between a project manager (responsible for the quality or performance of a project) and programme managers or senior executives ('Enterprise Management' as shown in Figure 8), who worry about quality or performance of individual projects only insofar as they impact growth and profitability objectives.

It is important to distinguish between an employee and the role fulfilled by an employee at any one time. People with one job title will generally perform multiple roles, and some roles may be shared between multiple people. MSSL's Technology Management Group researched this link between job title and role in a research project for GlaxoSmithKline's High Throughput Chemistry R\&D facility and found that understanding the relationship between roles is crucial in optimising system developments (Emes, Hughes et al. 2005).

\section{Example of relevance of principle for construction}

For too long, systems engineering and project management have been seen as completely distinct disciplines. This is particularly true amongst those sectors including construction that do not widely practise systems engineering; the only mention of systems engineering in the Association for Project Management's Body of Knowledge is in the glossary of terms (APM 2006). Managers of construction projects should view their projects from a systems perspective; this will help to understand and manage the flow-down of requirements from the stakeholders to the built system, and the interfaces between subsystems. Better understanding of interfaces will facilitate concurrent engineering - overlap between successive stages in the project lifecycle. It will also ameliorate the problem described previously of subsystem validation being impossible until the building is completed.

\section{Principle 5: Invest in the early stages of projects}

\section{Statement of principle}

For any activity in a project there will be a correct time to undertake it. Too early wastes resources while too late can lead to downstream adverse impacts. The optimum ordering of activities should be identified, resisting pressure to defer work until later for short-term reasons. Often this means that a project's ideal resource profile will be reshaped exhibiting an earlier peak (sometimes called 'left shift' of effort), with the expectation that this will lead to a reduction in the total effort required by the project, and a greater chance of project success. This approach can be extended upstream of the project, for instance investing resources in preparing for a future bid or even in predicting customer needs and future technology requirements. Above all, a project should be seen as an investment - it requires resources to be committed early on to deliver a (probabilistic) payoff later on (as major costs are avoided). Like other 
investments, projects should be seen as part of a portfolio of activities (a programme) that also needs to be optimised holistically.

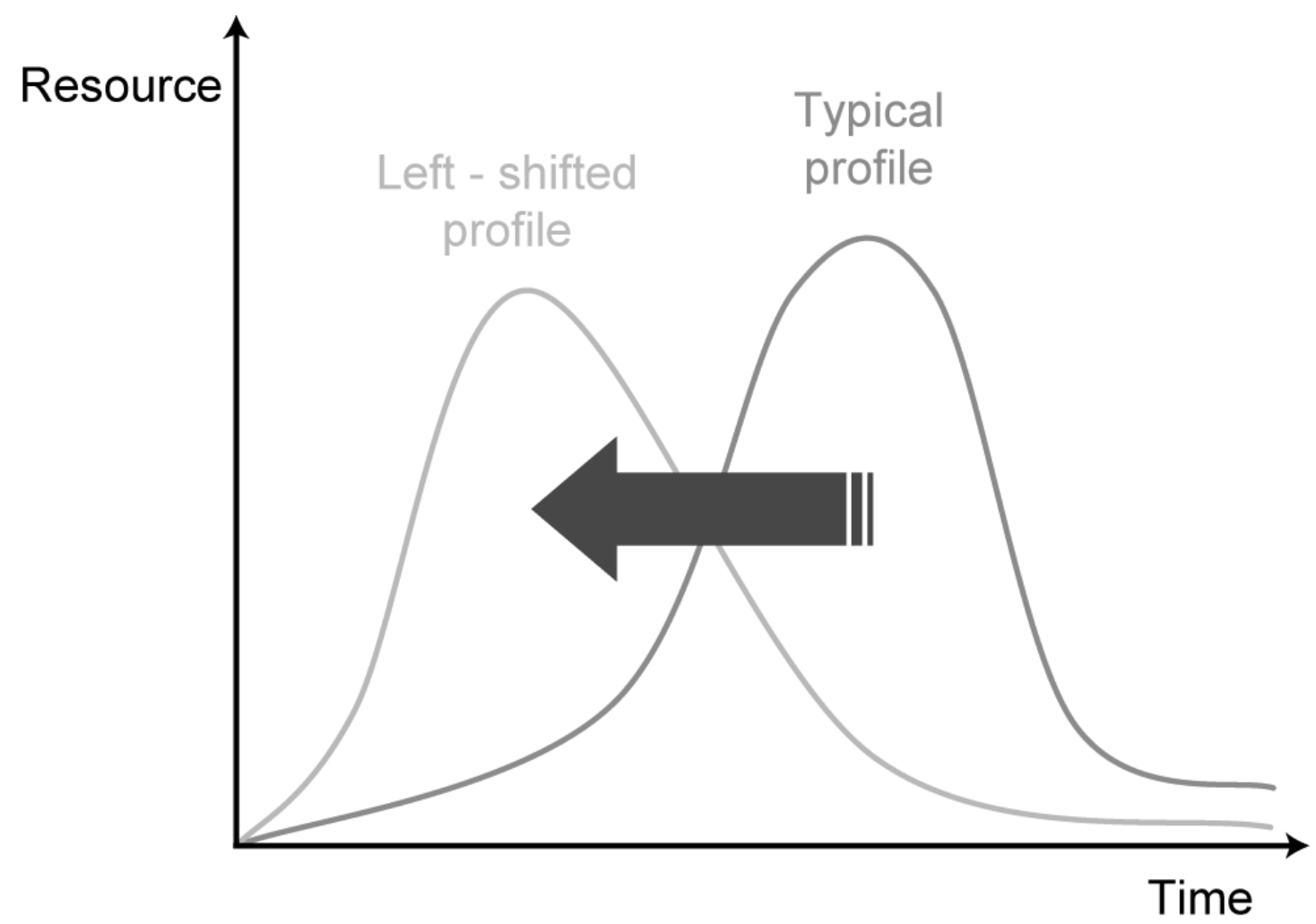

Figure 9: Invest in the early stages of projects

\section{Justification of principle}

It can be argued that in the time taken to accrue the first $20 \%$ of actual costs of a project, $80 \%$ of the total lifecycle costs are committed (INCOSE 2011). It is therefore essential that decisions in the concept and definition or development phases of projects be made with the benefit of good information and detailed analysis.

The idea of left shifting to invest effort in the early stages of projects will seem like common sense to most systems engineers, but there are many reasons why left-shifting may be resisted by project managers and senior executives (Emes, Smith et al. 2007). For example, the incentive to invest in the proposal-writing process to ensure that projected costs are accurate is weak - there is a 'conspiracy of optimism' (RUSI 2007). This is because project selection favours those projects that underestimate their costs, and for many major projects failure is not an option once a project is underway so escalation of costs rarely leads to project termination. This problem is exacerbated by the human tendency to be overly optimistic about the speed at which progress will be made and the likelihood of problems occurring (HM Treasury 2003).

Projects should be managed with a focus on achieving value for money (Kerzner and Saladis 2009). What this means in practice depends on the timing and conditions associated with costs incurred and income received and will involve some combination of value engineering (SAVE International 2011) and application of lean principles to avoid waste (Rebentisch, Rhodes et al. 2004). 
The value of investment is probabilistic in that there is no guarantee that increased cash flow will follow. Sometimes, such as when consortium building, the value to be obtained from early investment is primarily derived from an increased probability of winning a contract to supply a system; this value may never manifest. But even here, the consortium-building process may lead to valuable follow-on opportunities with project partners. Other times, the value may be derived from a reduced risk of project failure; more thorough planning can help to anticipate many problems that would normally be encountered in manufacturing or, worse, in service. It is difficult to retrospectively justify expenditure on the basis of avoidance of failure, but just as with insurance, the value is real. Long-run investment in capability ensures that when projects start, the tools and knowledge at the project team's disposal allow progress to be made relatively quickly.

The cost of space science missions can be very large (typically in excess of $\$ 500 \mathrm{~m}$ ) and can increase very significantly in the face of unforeseen technical difficulties. In order to ensure appropriate technical maturity across the lifecycle ESA (European Space Agency) and NASA gate their development process with the use of Technology Readiness Levels (TRLs). While this provides a useful check on the latter end of the process, it actually adds relatively little to what was already a well-understood process. However, it has had a particular impact upon the earlier stages, especially at the point of mission commitment where TRLs are expected to be greater than 5. MSSL needs to bring forward compelling and enabling technologies to a level of maturity that are of sufficient maturity to be selectable in a future mission. This involves often a very long-term programme of technological development targeted at key issues and designed to remove risk before commitment to a particular mission.

A goal at MSSL for some years has been to develop cryogenic coolers able to provide the very low temperatures demanded by state-of-the-art photon sensors. The preferred technology is adiabatic demagnetization refrigerators, which involve a complex configuration of paramagnetic elements, superconducting magnets, heat switches and thermal isolation. These need to be able to operate continuously in space and able to survive the stresses of a launch. While the challenge has been considerable, (not least in 'marketing' the feasibility to the scientific community) through a process of system design, modelling, identification and prioritization of technical issues, and innovative solutions, such as cooler has now been space qualified and is now undergoing a programme of mass reduction. This should lead to a flight instrument for the next generation of space science missions.

The appropriate amount to invest in systems engineering and in the definition stages of projects in general will depend on the circumstances of the project. Whilst research into NASA projects suggested around 15\% of project budget should be spent on the definition phase (Gruhl 1992), the most cost-effective activities to be undertaken in this phase, and the broad applicability to organisations of different sizes and maturities (and in different sectors) needs further investigation. 


\section{Example of relevance of principle for construction}

The high expense of retrospectively correcting design flaws in construction means that getting the design right in the first place is critical. Furthermore, the highly sequential nature of construction projects means that a relatively high proportion of construction projects' activities lie on the critical path - meaning that delays will lead to late delivery. It is particularly important in this case to invest adequately in the planning stage - understanding the stakeholder requirements and anticipating the complexity (in particular, interconnectedness between subsystems) of the delivered building.

\section{Conclusions and reflections for the construction industry}

Building design has traditionally assumed a simple sequential model, which poorly accounts for the effects of variations and delays within an iterative process such as design (Austin, Baldwin et al. 2000). This approach leads to progress monitoring which is entirely process driven, based on nominal achievement of arbitrary milestones, and not principle-driven based on real, value-adding progress in improving system maturity.

Even modern buildings often employ a relatively linear, sequential design process. De Wilde and van der Voorden (2003) investigated when and how decisions relating to energy-saving building components are made and found that are mostly made during the conceptual design phase with comparisons based on performance rare. Even when powerful modelling tools are employed, they are used to verify expectations or to optimize components already selected.

In most building design projects, the client gives only general design goals. Further design requirements, objectives, attributes and constraints frequently emerge during the design process. The early stages of building design are dominated by conflicting objectives and value judgments. In these circumstances, the traditional 'deterministic' model in construction of sequential planning, often combined with value-engineering focused project management, is ineffective (Green 1994). Whilst historically buildings have had one overriding function - to provide shelter - they are now created with a range of functional requirements enabled by ever-changing technology. The demands on those responsible for managing and designing major construction project have therefore changed.

Systems engineering emerged as a discipline to tackle projects requiring expertise that spanned functional disciplines - for example, electronics engineers had to work with structural engineers and thermal engineers. This is common practice in the space and defence sectors. But it is now also common practice in many other sectors including the design of 'intelligent' buildings, or at least it should be. The construction sector can therefore learn from taking a 'systems approach to design'.

By reflecting on its experiences in managing spacecraft technology projects over the last 45 years, MSSL has established a set of principles that capture the most important lessons learnt. The integrating theme behind the principles is to foster 
an ability to anticipate and respond to a changing environment with a constant focus on achieving long-term value for the enterprise. This value will primarily be associated with superior project performance, whether it be through increased performance of the delivered system (and therefore increased stakeholder utility), reduced development cost, reduced development time or reduced risk that one of the other three criteria will stray outside acceptable limits. One must not neglect, however, the value to the business of factors beyond the project, such as corporate reputation, opportunities for economically attractive follow-on projects, and the development of technological capabilities and a skilled and motivated workforce. The relationship between the principles is summarised in Figure 10.

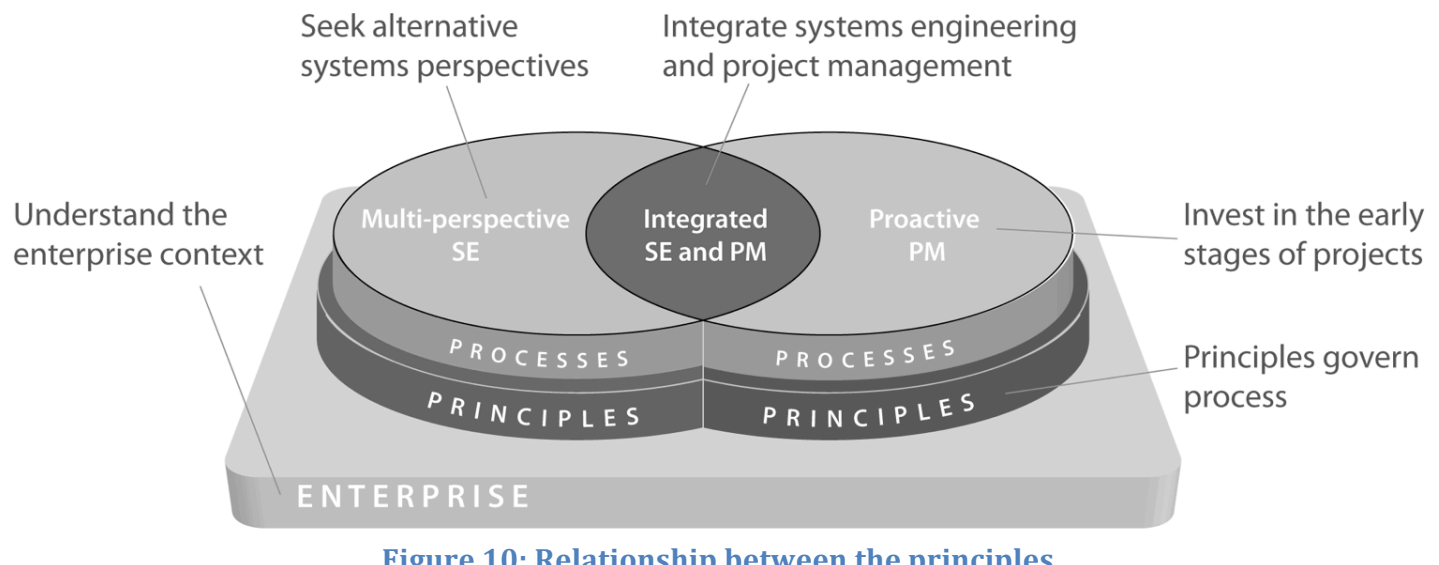

There will undoubtedly be barriers to the adoption of systems engineering in construction, perhaps related to its history and the relatively minor emphasis given to systems engineering in most books and training in project management (which has been widely adopted by the construction sector in the last thirty years). There is also a terminology issue that complicates the practice of systems engineering in construction, and that is around the use of the term 'architect'. Although the term is regulated around the world, the compound term 'systems architect' has been gaining popularity in systems engineering circles primarily to refer to those involved in top-level system design and representing the client's interests in a systems engineering project. There will be a tension between this and the traditional role of the architect in construction.

Nevertheless, although these principles were developed from experiences largely in the space sector, it is felt that they, and the practice of systems engineering in general, have much to offer for the construction sector.

\section{References}

APM (2006). APM Body of Knowledge - 5th Edition, Association for Project Management.

Augenbroe, G. (2011). The role of simulation in performance based building. Building Performance Simulation for Design and Operation. J. L. M. Hensen and R. Lamberts, Routledge. 
Augenbroe, G., Malkawi, A., et al. (2004). "A Performance Based Language for Design Analysis Dialogues." Journal of Architectural and Planning Research 21(4): 321-330.

Austin, S., Baldwin, A., et al. (2000). "Analytical Design Planning Technique (ADePT): A Dependency Structure Matrix Tool to Schedule the Building Design Phase." Construction Management and Economics 18(2).

BBC. (2012). "Millennium Bridge." Retrieved 21-Mar, 2012, from http://news.bbc.co.uk/hi/english/static/in_depth/uk/2000/millennium_ bridge/default.stm.

Brealey, R. A., Myers, S. C., et al. (2005). Corporate Finance. New York, McGraw Hill.

CCS. (2012). "Considerate Constructors Scheme." Retrieved 23-Mar, 2012, from http://www.ccscheme.org.uk/.

Checkland, P. (1999). Systems Thinking, Systems Practice. Chichester, Wiley.

Checkland, P. and Scholes, J. (1999). Soft Systems Methodology in Action. Chichester, Wiley.

Chesborough, H. W. (2003). Open Innovation: The New Imperative for Creating and Profiting from Technology. Boston, Harvard Business School Press.

Curran, R., Abu-Kias, T., et al. (2010). A Value Operations Methodology for Value Driven Design: Medium Range Passenger Airliner Validation. 48th AIAA Aerospace Sciences Meeting Including the New Horizons Forum and Aerospace Exposition. Orlando FL.

de Wilde, P., Augenbroe, G., et al. (2002). "Design analysis integration: supporting the selection of energy saving building components." Building Environment 37: 807-816.

de Wilde, P. and van der Voorden, M. (2003). Computational Support for the Selection of Energy Saving Building Components. Building Simulation 8th International IPBSA Conference, Eindhoven, Netherlands.

DoDAF. (2012). "Department of Defence Architecture Framework Version 2.02." Retrieved 22-Mar, 2012, from http://dodcio.defense.gov/sites/dodaf20/.

DSMC (1983). Systems Engineering Management Guide. Fort Belvoir VA, Defence Systems Management College.

Emes, M. R. (2007). "Strategic, Multi-Stakeholder Trade Studies." INCOSE Insight 10(1): 17-23.

Emes, M. R., Hughes, I., et al. (2005). Internal Invention, External Development. R\&D Management Conference. Pisa.

Emes, M. R. and Smith, A. (2005). Introducing new technologies in farming Getting it right second time. International Council on Systems Engineering UK Spring Conference. Swindon.

Emes, M. R., Smith, A., et al. (2007). Left-Shift vs The Time Value of Money: Unravelling the Business Case for Systems Engineering. International Council on Systems Engineering UK Spring Conference. Swindon.

European Cooperation for Space Standardization. (2011). Retrieved 06-Nov, 2011, from http://www.ecss.nl/.

FIDIC (2004). Improving the quality of construction: a guide for actions, International Federation of Consulting Engineers.

Folwell, K., Sharp, G., et al. (2011). UK Industry Performance Report, Strategic Forum for Construction.

Giachetti, R. E. (2010). Design of Enterprise Systems. Boca Raton FL, CRC. 
Gianni, G., Lindman, N., et al. (2011). Introducing the European Space Agency Architectural Framework for Space-based Systems of Systems Engineering. Complex Systems Design and Management. Paris.

Goode, H. H. and Machol, R. E. (1957). System Engineering. An introduction to the design of large-scale systems. New York, McGraw Hill.

Green, S. D. (1994). "Beyond value engineering: SMART value management for building projects." International Journal of Project Management 12(1): 49-56.

Gruhl, W. (1992). Lessons Learned, Cost/Schedule Assessment Guide, NASA Comptroller's Office.

Haimes, Y. Y. (2009). Risk modeling, assessment, and management. Hoboken NJ, Wiley.

Hitchins, D. K. (2003). Advanced systems thinking, engineering and management. Norwood MA, Artech House.

HM Treasury (2003). The Green Book: Appraisal and Evaluation in Central Government. London, TSO.

INCOSE. (2011, 26 Jan 2007). "About INCOSE." Retrieved December, 2011, from http://www.incose.org/about/index.aspx.

INCOSE (2011). Systems Engineering Handbook. C. Haskins.

International Organization for Standardization (ISO) (2008). ISO 9001: Quality Management Systems - Requirements.

ISO/IEC 15288 (2002). Systems Engineering - Systems Life Cycle Processes.

Jenkins, G. M. and Youle, P. V. (1971). Systems Engineering. A Unifying Approach in Industry and Society. London, C.A. Watts \& Co. Ltd.

Kee, R. C. (1999). "Using economic value added with ABC to enhance productionrelated decision making." Journal of Cost Management (December): 3-15.

Kelley, T. (2001). The Art of Innovation. London, Profile.

Kerzner, H. and Saladis, F. P. (2009). Value-driven project management. Hoboken NJ, Wiley.

Liker, K. (2004). The Toyota Way: 14 Management Principles from the World's Greatest Manufacturer. New York, McGraw Hill.

Martin, J. N. (2004). The Seven Samurai of Systems Engineering: Dealing with the Complexity of 7 Interrelated Systems. International Council on Systems Engineering Annual Symposium, Toulouse, France.

Martin, J. N. (2008). "Using the PICARD Theory of Systems to Facilitate Better Systems Thinking." INCOSE Insight 11(1): 37-41.

Meng, X. (2011). "The effect of relationship management on project performance in construction." International Journal of Project Management (in press).

Moeller, S. and Brady, C. (2007). Intelligent M\&A: Navigating the Mergers and Acquisitions Minefield. Chichester, Wiley.

NASA (1997). Maintaining U S leadership in aeronautics : scenario-based strategic planning for NASA's aeronautics enterprise, National Academy Press.

NASA (2007). NASA Systems Engineering Handbook. Washington DC.

National Audit Office (2011). Ministry of Defence: The Major Projects Report.

Phaal, R., Farrukh, C., et al. (2003). "Starting-up roadmapping fast." ResearchTechnology Management 46(2): 52-58. 
Rebentisch, E., Rhodes, D. H., et al. (2004). Lean Systems Engineering: Research Initiatives in Support of a New Paradigm. Conference on Systems Engineering Research. University of Southern California, Los Angeles CA. RUSI (2007). The Conspiracy of Optimism. RUSI Defence Systems: 60-65.

SAVE International. (2011). Retrieved 07-Nov, 2011, from http://www.valueeng.org/.

Senge, P. M. (1990). The Fifth Discipline: Art and Practice of the Learning Organization. New York, Doubleday.

Shell. (2011). "Looking ahead: scenarios." Retrieved 06-Nov, 2011, from http://www.shell.com/scenarios/.

Shishko, R., et al. (1995). NASA Systems Engineering Handbook. R. Cassingham, National Aeronautics and Space Administration.

Sterman, J. D. (2000). Business Dynamics: Systems Thinking and Modeling for a Complex World. Boston MA, Irwin McGraw-Hill.

Tao, R. and Tam, C.-M. (2011). "System reliability optimization model for construction projects via system reliability theory." Automation in Construction(in press).

The Standish Group (1994). The Chaos Report.

Torbett, R., Salter, A., et al. (2001). Design Performance Measurement in the Construction Sector: A Pilot Study. Brighton, UK, SPRU, Sussex University.

TRAK. (2012). "TRAK Enterprise Architecture Framework." Retrieved 22-Mar, 2012, from http://trak.sourceforge.net/.

van der Heijden, K. A. (1996). Scenarios: The Art of Strategic Conversation. Chichester, Wiley.

Westerman, H. R. (2001). Systems Engineering. Principles and Practice. Norwood MA, Artech House.

Wilson, B. (2001). Soft Systems Methodology: Conceptual Model Building and its Contribution. Chichester, John Wiley \& Sons Ltd.

Workman, J. P. (1993). "Marketing's Limited Role in New Product Development in One Computer Systems Firm." Journal of Marketing Research 30(4): 405-421.

Yahiaoui, A., Sahraoui, a.-E.-K., et al. (2006). A System Engineering Environment for Integrated Building Design. EuSEC European Systems Engineering Conference. Edinburgh.

Zachman, J. (2012). "The Zachman Framework." Retrieved 22-Mar, 2012, from http://www.zachman.com. 